\title{
DISCIPLINA SOCIAL Y ORGANIZACIÓN INTERNA DE LA CÁRCEL. SINTESIS DEL ESTUDIO DE UNA PRISIÓN CATALANA*
}

\author{
José Adelantado Gimeno \\ Profesor del Departamento de Sociologia. Universitat Autònoma de Barcelona
}

Resumen

El articulo muestra los principales resultados obtenidos a partir de una investigación sobre la cárcel, centrándose en la construcción del orden interno y en el cambio disciplinar. En primer lugar se interpreta la clasificación y el tratamiento penitenciario desplegados por la $L O G P$, como elementos que redefiner el espacio fisico y las relaciones sociales que sustenta. A continuación, se critica el funcionamiento del sistema de fases progresivas puesto en marcha por la $G e-$ neralitat de Catalunya, destacando su eficacia en la gestión del conftucto y en la consecución de la paz institucional como objetivo politico. Seguidamente, se contemplan los efectos del sistema de fases respecto de la estratificación de presos en diferentes stubclases, y se observan las consecuencias disciplinares que comporta este sistema al conjugar clasificación y tratamiento. Finalmente, se realiza un and́lisis de la organización carcelaria para poner de relieve la bondad del sistema en la producción del orden interno desde una comunicación alienada. El articulo concluye que el sistema de fases, lejos de estar encaminado a la resocialización, como prescribe la Constitución, se incardina en lo que pueden constituir nuevas formas disciplinarias y de construcción del orden en el interior de la cárcel.

Resum

L'article mostra els principals resultats obtinguts a partir d'una investigació sobre la presó, $i$ se centra en la construcció de l'ordre intern $i$ en el canvi disciplinar. En primer lloc, s'interpreta la classificació $i$ el tractament penitenciari desplegats per la LOGP, com a elements que redefineixen l'espai fisic i les relacions

"Para ta confección de este artículo he utilizado parte del material correspondiente a una investigación empirica financiada por el Centre d'Estudis Juridics i Formació Especialitzada del Departament de Justícia (Generalitat de Catalunya) llevada a cabo durante el mes de julio de 1991 en la cárcel de "Quatre Camins" (Barcelona). En el texto, las notaciones GP, AT, AR e IN, seguidas de un número, corresponden a 35 entrevistas de investigación realizadas a 5 Gestores Políticos (GPn), 9 funcionarios del Área de Tratamiento (ATn), 11 funcionarios del Area de Régimen $(A R n)$ y a 10 internos (INn).

Agradezco a Pilar Carrasquer, a María Jesús Izquierdo, a Celia Suay y a Teresa Torns sus valiosos comentarios a las páginas que siguen. 
"Papers": Revista de Sociologia

socials que sosté. A continuació, es critica el funcionament del sistema de fases progressives posat en marxa per la Generalitat de Catalunya, i es destaca la seva eficacia en la gestió del conficte i en la consecució de la pau institucional com a objectiu politic. Tot seguit, es contemplen els efectes del sistema de fases en relació amb l'estratificació de presos en diferents subclasses, i s'observen les conseqüencies disciplinars que comporta aquest sistema en conjugar classificació $i$ tractament. Finalment, es realitza una analisi de l'organitzacio de la pressó per tal de posar en relleu la bondat del sistema en la producció de l'ordre intern des d'una comunicació alienada. L'article conclou que el sistema de fases, lluny de l'objectiu resocialitzador que la Constitució estableix, s'incardina en el que poden constituir noves formes disciplinàries $i$ de construcció de lordre a l'interior de la presó.

Abstract

The article shows the main results which stem from a reserch about the prison, focusing on the construction of internal order and on disciplinary change. First, the clasification and the penitentiary treatment developed by the $L O Q P$ are interpreted, as elements which redefine the space and the social relations which it sustains. Thereafter, the working of the progressive phases system implemented by the Catalan Autonomous Government is critictsed, emphasizing its eficacy in the management of conflict, and in the consectution of institutional peace as a political objective. Then, the effects of the system of phases in relation to the stratification of prisoners in different subclasses are considered, and the disciplinary consequences are observed which this entails since it combines classification and treatment. Finally, an analysis of prison organization is conducted, in order to show the consistence of the system in the production of internal order from an alienated communication. The article concludes saying that the system of phases, far from resocialization, as the Spanish Constitution points out, articulates itself in what constitutes new disciplinary forms, and those of order building inside the prison.

A partir de los setenta, las sociedades de capitalismo avanzado sufren profundos cambios y empieza a configurarse un nuevo orden cultural ${ }^{1}$ que conlleva cambios en la construcción del orden social y de la disciplina. La cultura del darwinismo social que impera en la actualidad hace cómplice al individuo de su propia represión. Debe ser él mismo quien se autoimponga aquello a lo que la sociedad le obliga.

En el terreno carcelario las nuevas formas de disciplina están en relación con los cambios socioculturales enunciados. Los países que pusieron en marcha alternativas comunitarias a la pena privativa de libertad, eran aquelios en los cuales la lógica del capitalismo fordista había sido amortiguada mediante

1. Pot "orden cultural" entiendo el conjunto de relaciones simbólicas que se establecen en el campo ideológico o de la cultura que, siendo expresión del conflicto entre los grupos o las clases, consticuye la esencia de legirimidad de un orden de dominacion (C. Lerena, 1986, J. Habermas, 1981, J. Adelantado, 1992). 
un amplio despliegue del Estado del Bienestar ${ }^{2}$. Las críticas a la prisión se pretendieron compensar mediante la ideología resocializadora, que comportaba una difusión del control y permitía la puesta en práctica de procedimientos que redefinian el espacio físico. Pero la propia ideología resocializadora ha sido objeto de una nueva orientación al estar implicada en el cambio global del modo de dominación. La fragmentación y polarización social tiene su contrapunto en la cárcel por medio de los nuevos sistemas de clasificación, mientras que el tratamiento penitenciario se utiliza como vehículo de gestión del conflicto, y opera como instrumento disciplinar.

El modelo disciplinar encarnado por el carcelero está dando paso a otro que pretende la corresponsabilización con los objetivos de la institución. Este modelo emergente afecta simultáneamente a dos dimensiones cruciales en la construcción del orden en la prisión. Por un lado, a la distribución de los internos sobre el espacio físico y, por otro, al tipo de relaciones sociales que se establecen. Los procedimientos clasificatorios y el tratamiento penitenciario son los elementos que se conjugan en la producción del orden interno. Diriase que, en conjunto, lo que se ofrece a los internos bajo una nueva forma de contrato social es una prostitución moral que no se basa en la sumisión a mecanismos de control personal, sino en manifestar una lealtad al poder ante la expectativa de obtener recompensas individuales. La autosubordinación opera mediante la sustitución de potenciales de conflicto por connivencias con el poder; pues cualquier sujeto negocia para mantener o mejorar sus condiciones de vida.

El objetivo de este artículo es mostrar algunos procedimientos disciplinares que tienen lugar en la cárcel. En la primera parte se introduce al lector en los elementos básicos de la actual clasificación y tratamiento penitenciario de los internos. En la segunda, se profundiza en el sistema de fases como herramienta que conjuga la fragmentación espacial y la segmentación de presos en categorías. En tercer lugar señalo la dinámica disciplinar inherente a los procesos de discriminación y de participación en la construcción del orden interno. Finalmente, se aborda la gestión de la prisión como modelo disciplinar, alejado de cuałquier meta resocializadora.

\section{CLASIFICACION Y TRATAMIENTO}

La distribución y agrupación de presos en base a algún criterio clasificatorio es, incluso, más antigua que la propia pena privativa de libertad ${ }^{3}$. En la

2. Una panorámica sobre las estrategias de control en el capitalismo maduro puede encontrarse en: ]. Lea (1979); F. Stame (1979); D. Melossi (1980 y 1990); A. Scull (1984); S. Cohen y A. Scull (1985); J. Lowman, R. J. Menzies y T. S. Palys (1987); S. Cohen (1988).

3. Carlos I ya ordenó la separación de hombres y mujeres. A finales del siglo XVIII se asiste 
actualidad, la clasificación orientada a la resocialización hasta tal extremo resulta consustancial a la prisión, que se puede afirmar que constituye su espina dorsal ${ }^{4}$. En el caso de España, el elemento más reciente y notorio es la clasificación desplegada con la LOGP (Ley Orgánica General Penitenciaria), en 1979. La ley señala distintos tipos de centro, grados de clasificación y, aún dentro de cada grado, se producen otras segmentaciones que distribuyen a los internos en diferentes módulos. La legitimidad de la moderna clasificación reside en el tratamiento de los penados. La clasificación y el tratamiento penitenciario son dos instrumentos cuya interrelación en el seno de la prisión implicaría, desde una óptica resocializadora, un orden de prioridades en el que la primera debería estar subordinada al segundo (B. Mapelli, 1986b). Pero de hecho, como se reconoce, "en el primer decenio de la LOGP la tarea de clasificación, tan fundamental en el quehacer penitenciario, es la que ha llegado a un mayor grado de desarrollo, mientras que las tareas de programación y ejecución de métodos de tratamiento, siguen sin tener entidad pese a la claridad legal» (J. Alarcón Bravo, 1989: 16).

La organización del espacio carcelario durante el franquismo ponía en contacto a multitudes relarivamente homogéneas en sus condiciones de clase. Las relaciones sociales entre los internos se traducían en formas organizativas fundamentadas en la semejanza de sus condiciones de vida (verbigracia la $\mathrm{CO}$ PEL). El patio y la galería eran espacios de relación y los mecanismos por los cuales los individuos intentaban mejorar sus condiciones de existencia se traducian en formas de acción colectiva. Pero una posible redefinición del espacio físico permite, simultáneamente, incidir en los potenciales de conflicto de-

a un impulso diferenciador de penados por razones de higiene social. Ia Ordenanza General de Presidios de 1834 divide los internos en clases según la diligencia en el trabajo. Durante el último tercio del XIX y primera década del XX, se implanta definitivamente el sistema progresivo, convirtiendo, en parte, el derecho penitenciario en un derecho premial. En el importante Congreso de la Haya de 1950 se incidirá en la importancia de la clasificación con fines uratamentales y como garantía juridica.

4. Aunque la idea de resocializar a los condenados se remonra por lo menos al correccionalismo decimonónico, roma auge en la década de los cincuenta y sesenta. Se asume que el delito tiene componentes psicosociales y que, por tanto, el fin de la pena debe ser la ayuda al condenado por medio del tratamiento para su reeducación y readaptación. Esa formulación será duramente contescada en los años sucesivos. Numerosos autores (entre otros: R. Bergalli, 1976; F. Muñoz Conde, 1982; A. Baratta, 1986; B. Mapelli, 1983) darán cuenta del contrasentido que supone pretender liberar reprimiendo y de la imposibilidad de resocializar privando de libertad. Pero a pesar de las críticas, la idea de recuperar socialmente al condenado mediance el tratamiento penitenciario alcanzará notoriedad juridica a partir de mediados de los setenta (ley penitenciaria italiana de 1975, ley alemana de 1976). En España, el art. 1 de la LOGP, y más aun la misma Constitución (art. 25.2), señalan que ulas penas privativas de libertad y las medidas de seguridad estarán orientadas hacia la teeducación y teinserción social». 
rivados de la coincidencia, y en la ordenación de jerarquías que ejercen el poder (M. Foucault, 1988).

La nueva codificación del espacio puesta en marcha con la LOGP, ha aumentado las posibilidades de ubicación y descentralizado el espacio panóptico. $\mathrm{La}$ fragmentación del espacio carcelario en diferentes unidades ha reducido la posibilidad de concentración de presos y, con ello, dificultado la posibilidad de una conciencia grupal y el establecimiento de estrategias de carácter colectivo. Los internos dan cuenta de la fragmentación en los mecanismos de identificación grupal, y advierten la sustitución de dinámicas colectivas de integración, conflicto y control, por otras de carácter individual ${ }^{5}$.

Si la clasificación es el eje para la distribución espacial, el tratamiento es el dispositivo para las nuevas relaciones disciplinares. En todos los trabajos consultados sobre el tratamiento penitenciario ${ }^{6}$ aparece la cuestión de qué se entiende por tal. Aquí no se va a entrar en esa discusión; por contra, sefialaré algunos puntos de interés para entenderlo desde sus implicaciones disciplinares.

1) En los textos jurídicos, la expresión "tratamienton es poco precisa, y su interpretación puede utilizarse para multitud de fines. Por ejemplo, según se enfoque y practique el tratamiento, ¿cómo se distingue una institución formalmente terapéutica, tal como la cárcel se presenta hoy, de una instancia estigmatizante?.

2) Se justifica la existencia de la clasificación como condición necesaria para el tratamiento, pero a su vez, clasificación y tratamiento se encuentran vinculados al sistema progresivo de modo tal, que el tratamiento puede acabar por convertirse en un sistema premial coincidente con la mera actividad clasificatoria. Por ejemplo, ¿en base a qué criterios resocializadores se regresa de grado a un interno, situándolo en un ambiente más perjudicial para la acción terapéutica?

3) Los beneficios penitenciarios se hacen depender de la evolución del tratamiento. Pero, aunque es necesario el consentimiento del interno para ser tratado, no ejercer ese derecho obstaculiza el acceso a ciertos beneficios. Los operadores penitenciarios retienen una parte importante en la ejecución de la

5. "Antes habia más apoyo entre los compañeros, era más facil que se organizara un plante, ahora cada uno mira para sí mismo" (IN8), «Antes sí que había una cultura penitenciaria, ahora no" (ATS). "Desde que entro tratamiento se ha roto cualquier mecanismo de solidaridad y de compañerismo, cada uno va a la suya" (IN2).

6. R. Bergalli (1976), F. Muñoz Conde (1982 y 1985), L. Garrido Guzmán (1983), B. Mapelli (1983, 1985, $1986 a$ y 1986b), A. García-Pablos (1984), J. García García (1987b), V. Garrido Genovés (1986 y 1987), J. Alarcón Bravo (1989). 
pena que puede afectar a las garantías jurídicas de los internos e, incluso, el propio tratamiento puede convertirse en un recurso organizativo, ajeno a la terapia. Por ejemplo, los contactos con el exterior (tal vez el beneficio más apreciado por un penado), que dependen en principio de la evolución en el tratamiento, pueden ser utilizzados para pacificar la prisión.

4) Si la expresión "tratamiento" resulta vaga en los textos jurídicos, no lo es menos la de su "evolución". Sin embargo, la calidad de vida en la prisión y las posibilidades de redimir pena, se determinan por la valoración que se hace de la "evolución del tratamiento". Ni en la evaluación ni en la definición de los contenidos del tratamiento intervienen los internos. Así, puede ocurrir que la evolución sea favorable cuando la conducta del interno sea merecedora de mayor confianza para los evaluadores, y desfavorable cuando haya oposición o resistencia al tratamiento. La participación del interno quedaría reducida a una complicidad conductual con los patrones de integración definidos por los gestores de la organización.

\section{CLASIFICACIÓN, TRATAMIENTO Y SISTEMA DE FASES}

En Cataluña, clasificación y tratamiento convergen en la prisión a través del sistema de fases progresivas cuyo cometido principal es incidir en la conducta de los internos a fin de reeducarlos y reinsertarlos ${ }^{7}$. La clasificación, desde una óptica resocializadora, debería estar subordinada al tratamiento. Pero lejos de eso, el "Programa de Classificació en els Centres Penitenciaris" aplicado desde 1988 en todos los centros gestionados por la Generalitat y que tiene sus orígenes en la experiencia piloto del sistema de fases iniciada en el Cen-

7. Para sus formuladores ( $S$. Redondo, M. Roca, y P. Portero (1986), los componentes principales del sistema de fases progresivas son:

1) Escablecimiento de un grupo de programas dirigidos al logro de mejoras en cl proceso de socialización de los internos y tendentes a disminuir la conflictividad.

2) Estructuración del centro en cuatro unidades de clasificación diferenciadas según: a) La exigencia en la emisión de comportamientos definidos en los programas, y b) La existencia de reforzadores asociados a cada unidad de clasificación.

3) Asignación inicial de los internos a una de escas unidades de clasificación rras un estudio de sus posibilidades comportamentales por el Equipo de Tratamiento del centro.

4) Revisión periódica por parte de ese mismo equipo, realizándose cambios hacia unidades superiores o inferiores de manera contingente con el tipo de conductas definidas en cada fase. A medida que los internos emiten las conductas exigidas, progresan de fase y obtienen mayores gratificaciones $y$, a la inversa, sufren una merma en las ventajas institucionales.

5) Información sobre el sistema y su funcionamiento a todo el personal del centro y a los propios internos. 
tro de Jóvenes de Barcelona en 1984, prioriza el elemento distributivo (F. Elejabarrieta, S. Perera y A. Ruiz, 1991). A pesar de las coincidencias teóricas entre ambos, la Administración Autonómica, al priorizar la clasificación sobre el tratamiento mueve a pensar que el objetivo prioritario no era tanto la resocialización como la dispersión de presos ${ }^{8}$.

El sistema de fases progresivas, además de su vertiente clasificatoria, introduce un elemento dinámico que permite obtener ventajas institucionales. Así que los internos participan en los programas de actividades que propone el centro, y así que se respetan las normas de la institución, acceden a una mejor calidad de vida, a permisos penitenciarios, y a reducciones de condena. La variable que une el programa conductual de las fases y la clasificación, son las actividades. Las actividades optimizan el recurso del espacio y del tiempo llenándolos de significado? ${ }^{9}$. En el modelo de vigilancia asociado al panóptico, el espacio y el tiempo eran dimensiones vacías, pero el moderno tratamiento los convierte en espacios y tiempos útiles. A medida que los internos conceden más de su tiempo a la institución y se distribuyen en espacios diferenciados para realizar las actividades, acceden a mayor libertad de movimiento tanto dentro como fuera de la prisión ${ }^{10}$.

La circunstancia de operar sobre la distribución espacial y el uso del tiempo a través del sistema de fases, trastoca el equilibrio de poderes en el scno de la

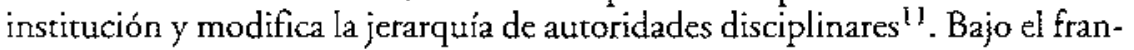
quismo, la estructura de autoridad en las cárceles era deudora de los mejores métodos de subordinación jerárquica ensayados en las organizaciones militares. El poder sobre los reclusos lo ejercía el carcelero, pero la clasificación

8. "El programa de clasificación interior pata la conflicrividad y la esrabilidad funciona" (AT4). "Las fases han servido para dividir a los internos, facilitan la paz inscitucional y nada más" (AR7). "El programa de fases funciona para la vida regimental porque permite distinguir entre buenos, menos buenos, malos y muy malos; sirve para estratificar, pero no sirve para reeducar" (AR 1 1). "El sistema de fases es una técnica más que organiza la vida interna y mejora el clima social de la prisión” (GP4).

9. En este sentido hay que scr̃alar dos campos de acción del poder institucional: las invesugaciones sobre el clima social, y las técnicas para modificar la conducta. Sobre las primeras pueden consultarse los siguientes trabajos: V. Sancha Mara (1987); J. Garcia García (1987a y 1987 b); S. Redondo, V. Garrido y E. Pérez (1988); S. Redondo, M. Roca, E. Pérez, A. Sánchez y E. Deumal (1990). Y sobre las segundas: J. Garcia Garcia (1985); S. Redondo, M. Raca y P. Portero (1986); S. Redondo Illescas (1990a); S. Redondo, M. Roca y E. Pérez (1991). En ambos sentidos y sobre el análisis de caso que nos ocupa, consultar el "Programa de Clasificación Interior C.P. Quatre Camins" de la Subdirección de Tratamiento del cencro.

10 «Eso provoca el ansia de participar en lo que sea para pojer tener algo más de movimiento y libertad sobre el espacio fisicon (IN/4).

11. "En esta prisión pretenden regir el tiempo y el espacio del interno a través de las fases $y$ las actividade5" (IN4). "Los funcionarios to que han visto es que antes movían a los internos a su antojo, $y$ ahora lo hace el tratamicnto, $y$ claro, les fastidia" (AT9). "Se ceme más a los profesionales que a los funcionarios" (IN3). 
orientada a la resocialización recompone el poder sobre los internos transfiriéndolo del "Área de Régirmen" a la de "Tratamiento" "2. En estos momentos la figura que dispone potencialmente del tiempo de los reclusos es el Equipo de Tratamiento por medio de la obligatoriedad de participar en los programas de actividades que propone.

El control por medio del tratamiento se diferencia de la vieja vigilancia porque utiliza criterios distintos para valorar la relación que establecen los internos con el tiempo y con el espacio. A menos actividades corresponde mayor limitación física y mayor presencia de la vigilancia ${ }^{13}$. Participar en actividades conlleva la posibilidad de tener más movilidad y menor control estrictamente visual, a cambio de aceptar la supervisión de las relaciones sociales que se establecen sobre un espacio y un tiempo optimizados como recurso disciplinar. El tratamiento y la vigilancia son dos modelos disciplinares que establecen diferentes formas de relación con el tiempo y con el espacio. La vigilancia visual tiene su apogeo en los "patios" de las prisiones como espacios masificados e indeterminados. El tratamiento, a través de la acción comunicativa de participar, jerarquiza el uso del espacio y del tiempo y conileva un elemento disciplinar que conmina a los individutos a participar en lo que propone la institución. La redistribución del tiempo y del espacio es operativa porque introduce una economía que otorga valores crecientes así que el individuo se somete a un tiempo y espacio con "sentido". El elemento disciplinar consiste en autosubordinarse y colaborar en consegutir los objetivos de la organización a cambio de obtener ventajas individuales ${ }^{14}$.

El sistema de fases progresivas, además de posibilitar ventajas en la calidad de vida en prisión, otorga ciertos premios. El principal consiste en la obtención de permisos de salida. La legitimidad del premio se sustenta en opiniones doctrinales proclives a las ideas resocializadoras: facilitar la progresiva integración social del recluso; sin embargo, wen la LOGP los permisos son contemplados no como elemento resocializador sino de control interior: la materia concerniente a los permisos de salida constituye un capítulo autónomo, el VI, artículos 47 y 48, dentro del Título II dedicado al Régimen pe-

12. La similitud entre la fábrica y la cárcel respecto a la expropiación de un espacio de tiempo de las personas ha sido analizada por E.B.Pasukanis (1970), pero si se tiene en cuenta no sólo el aislamiento espaciorcmporal, sino también la dinámica de relaciones que se establece, podremos identificar las nuevas figuras que ejercen el control inmediato sobre el tiempo de los aislados.

13. "Los talleres y las actividades sirven para quitarse de los funcionarios y del patio" (IN9). "Las fases han servido para tener a menos gente en los patios" (AR7).

14. "Es obligado participar, si no, te quedas sin beneficios y además re cogen ojeriza" (IN9). "Si el tratamiento no Hlevara aparejada la redención no se harían las actividades" (AR10). "Los internos lo primero que preguntan para apuntarse a una actividad es si redime. Todo está enfocado a salir pronto y a conseguir un nivel de vida mejorn (AR5). 
nitenciario. Pero, tratándose de una de las instituciones más eficaces con que cuenta el moderno tratamiento penitenciario, debía haberse incluido en el Título IIl relativo al Tratamienton (L. Garrido Guzmán, 1989: 92). En csa dirección de concebir los permisos como instrumento de vigilancia y custodia, los funcionarios del Ârea de Tratamiento cumplen una función "más de control que como reeducación" (AT9). "El educador se usa para reducir conflictos" (AT5).

Los permisos de salida utilizados como elemento de control, reformulan las autoridades jerárquicas y se convierten en agentes centrales en la construcción del orden interno: "los permisos sirven para mantener la paz" (AR10). "La dirección lo que no quiere son conflictos; si los internos arman líos con los demás se quedan sin salir» (AT3). La utilización de los permisos por parte de la Administración Penitenciaria como elemento de gestión del orden se articula con la clasificación y el tratamiento del sistema de fases progresivas: "los internos entienden la progresión como más permisos» (AT4). Las ventajas penitenciarias habrían de ser el premio a la adquisición de habilidades psicosociales, sin embargo, en la práctica actúan como contenedoras de la tensión institucional ${ }^{15}$. No se duda de que los gestores penitenciarios sean partidarios de la resocialización, todos lo afirman, pero también es clara la prioridad de contener el conflicto, tanto políticamente como condición necesaria para la reeducación.

La paz institucional pasa a constituir el principal objetivo de la gestión carcelaria, mientras que la resocialización queda relegada a una meta sccundaria y subordinada al orden interior ${ }^{16}$. Se prioriza la clasificación-dispersión sobre el tratamiento, y se le asocia un elemento dinámico como son los permisos penitenciarios que subliman el orden interior. «Pisar calle», lejos de ser un momento en un continutm tesocializador, es la consecuencia de intercambiar potenciales de conflicto por paz institucional. Los permisos penitenciarios actúan como recurso organizativo regulador del conflicto por medio de asignar valores ordinales a una fragmentación del tiempo y del espacio. De ese modo, el sistema de fases progresivas se combina estratégicamente con la preeminencia de la clasificación-dispersión y tiende a desvincularse de la reeducación y mucho más del régimen abierto como paso siguiente en un proceso de resocialización comunitaria.

15. "La prisión estallaría si se cortasen los permisos" (IN1). "Lo único que se pretende es rener a la población rranquila" (AR9). "Con las acrividades se dan redenciones por un tubo para que se esrén callados" (AR8). "Se confunde rehabilitación con actividades para darkes permisos $y$ redenciones" (ARII).

16. "Si un interno progresa es para conseguir su permiso, esa es la única morivación" (AR9). "Para "pisar calle" hay que hacer una serie de actividades, pero lo único que interesa es el permiso: (IN 10). 


\section{SEGMENTACION, PARTICIPACION Y DISCIPLINA}

El sistema de fases provoca una estratificación en los internos que esconde mecanismos redistribuidores de la desigualdad entre los propios penados. La clasificación y el tratamiento practicado por el sistema generan una estratificación teconocida por los mismos gestores políticos que, según los internos, "lo que hacen es diseccionar los derechos según fases" (IN3); como consecuencia, las condiciones de vida se ven afectadas por la reordenación de la miseria de modo que "los presos ven las fases como discriminatorias y a menudo dicen que son marginados y que las fases aún los marginan más" (AT5) ${ }^{17}$.

El programa de clasificación interior selecciona internos participativos y que tengan conductas adaptadas. Su localización en una fase u otra responde a la evaluación de su participación en los objetivos de la institución. A consecuencia de ello se produce una penalización de aquellos individuos que se muestran remisos a colaborar ${ }^{18}$, al tiempo que llegan a las fases más altas aquellas personas que la institución valora como stjjetos de buten pronóstico ${ }^{19}$.

La construcción social de la diferencia que produce el sistema de fases, provoca sentimientos de desprecio y envidia entre los mismos internos, que tiene importantes efectos para la fragmentación de las identidades colectivas, para la modulación del conflicto y para la justificación y eficacia de la propia desigual$\mathrm{dad}^{20}$. En realidad, lo que ocurre es que cualquier procedimiento discriminatorio de ventajas o inconvenientes, necesira de unos mecanismos que lo legirimen: «el I es un ghetto, pero también es un punto de referencia para el IV" (IN3).

Los efectos de la clasificación se traducen en la formación de grupos relativamente homogéneos entre sí, pero ordenados verticalmente en cuanto a calidad de vida en la prisión. En la medida en que la pertenencia a los grupos y la calidad de vida que se disfrute, se haga depender del grado de conflicto entre el inter no y la institución, se pone en marcha un mecanismo desactivador de

17. Lejos de responder a caracteristicas individuales, los estratos agrupan a individuos que se mueven en modelos culturales similares, que se manifiestan en el tipo de delito y de condena. "Los internos del IV son mayores, con condenas largas, violadores, asesinos; sujeros no excesivamente marginales. La marginación clásica se encuentra en el mbdulo I" (ARI). "Los del IV rienen deliros pasionales, económicos, tráfico a gran escala, y tienen un relativo nivel cultural. Los del I vienen un tipo de delitos más violenton (IN3). "En el IV hay violadores y en el I atracadores y drogadictos" (IN6).

18. "A la gente del I le cuesta más entrar en el tratamienton (AT9). "La gente del I no qujere cambiar" (AR1). "El interno tonto no cambia de fase, el inteligente se adapta" (AR9).

19. A cste respecto es interesante el trabajo de M. Martorell, (1989) "El procés d'incorporació social en una mosrra qualitativa d'ex-reclusos: la incidència de la presó en els seus usuaris".

20. "Las fases son un sistema de coacción que potencia el egoísmo del ser humano" (IN1). "El sistema de fases genera tirantez entre los miembros de las distintas fases y produce marginación entre tos propios marginados. A los del I se les llama "cafres", los del IV tenemos la fama de "chivatos y enchufados": (IN8). 
la discrepancia. Si además, la lealtad a la institución, esto es, al modelo de integración disciplinar que ella propone, es premiado con beneficios penitenciarios (permisos de salida, o mayor redención) cuando se participa en un ma. yor volumen de actividades, la clasificación adquiere su verdadera importancia como mecanismo regulador de la tensión institucional. Las expectativas de niveles de vida crecientes generadas por los sistemas de clasificación progresiva, son el estímulo necesario para forzar la participación, esto es, la integración vertical, $y$, a la inversa, amenaza a quien se opone al modelo de subordinación propuesto. Según la importancia que tenga la ausencia de conflicto como valor de gestión de la organización penitenciaria, la clasificación, ligada a la existencia de distintas calidades de vida (especialmente respecto a los contactos con el exterior), puede convertirse en un fin en sí misma, independientemente de la intensidad con que se ejecute cl tratamiento.

La meta resocializadora en el marco penitenciario ha jugado y está jugando un papel de superación de la crisis de la prisión. El componente ideológico dc la resocialización pretende legitimar el castigo bajo la forma de una ayuda compensatoria de déficits educativos (B. Mapelii, 1986a). La marginación y la desigualdad social son transformados en déficits personales para que la pena pueda definirse como ayuda. La influencia pedagógica en los procesos de control tiende a convertir a toda la sociedad en un continuum aula-cárcel ${ }^{21}$, en la que, por medio de relaciones comunicativas desiguales, poder manejar y dirigir los procesos de socialización y aprendizaje. En estas condiciones las metas resocializadoras operan como mecanismos de control e integración tendentes a evitar la disidencia y a asegurar la sumisión de los individuos a las prácticas que determina el poder con el fin de garantizar el mantenimiento del orden establecido.

El modelo etiológico-médico de tratamiento penitenciario supone la preeminencia del conocimiento técnico como variable estructuradora de la disciplina; según él, los delincuentes son enfermos y la clasificación es el resultado de identificar la enfermedad y aislar a sus portadores. El diagnóstico clínico, a partir del cual se establece la clasificación y se prescribe el tratamiento, es la manifestación de una estructuración del espacio y de las relaciones sociales que sobre él se establecen. El positivismo que subyace a este modelo médico hace que el tratamiento se centre en la curación y posterior rehabilitación del disfuncional-enfermo-delincuente-paciente, individualizando y descontextualizando su problemática social. No obstante, la curación a través del tratamiento clínico impuesta por la fuerza del diagnóstico, está dando paso al tratamiento por medio de la palabra. La enfermedad ha sido transformada en déficits educativos y sociales y el delito se presenta como una transgresión por

21. En este sentido son recomendables los trabajos de A. Baratta (1988) y el de L. Aniyar de Castro (1985). 
"desconocimiento" de las pautas normalizadas de integración ${ }^{22}$. La primera clasificación tiene por objeto detectar los déficits personales en el conocimiento de las normas sociales y compensar las insuficiencias con un plus de educación. Pero la clasificación originaria es el punto de partida; la reclasificación ascendente y descendente bajo el sistema progresivo, estimula la lealtad y el compromiso con los fines de la institución que, al basarse en un sistema meritocrático produce consecuencias individualizadas.

El modelo disciplinar encarnado por el carcelero, tendía a producir una integración pasiva y vigilada de los penados. Ahora, ese modelo disciplinar se combina con una integración que pasa por la interiorización de los objetivos de la institución y por la participación -alienada - en su consecución. La disciplina impuesta por figuras de autoridad se transforma en una autodisciplina estimulada y chantajeada por la posibilidad de obtener mejoras personales. Ese marco de valores dominante no necesita para imponerse de unas figuras represivas tan claras. Es suficiente transmitir las ventajas y desventajas que corresponden a las distintas fases de tratamiento, para estimular una competencia entre personas bajo ese sistema de premios selectivos así que se intercambian potenciales de conflicto por calidad de vida. En ese contexto, la posibilidad de obtener ventajas individuales requiere marcos de ubicación social y física relativamente reducidos, tanto para desanimar la posibilidad de obtener esas ventajas por medio de la acción colectiva, como para estructurar la subordinación disciplinar por procedimientos comunicativos asimétricos. El mejor penado no es el más obediente, sino aquél que es más cómplice con los objetivos de la institución. La integración ahora se mide por el grado de participación comunicativa en los procesos de definición de la realidad social. Aceptar un grado de participación subordinada en la definición de la realidad, es el eje de las nuevas formas disciplinares. La clasificación de los internos se incardina en ese proceso de producción del orden y, asociado al tratamiento, sienta las bases para una relación disciplinar basada en procedimientos comunicativos. Las nuevas autoridades disciplinarias no son los viejos carceleros, sino la pléyade de expertos en comunicación interpersonal y dirección de grupos que operan desde los equipos de tratamiento: psicólogos, educadores, trabajadores sociales, pedagogos ${ }^{23} \ldots$

22. Un buen trabajo histórico sobre la actividad de los expertos en el tratamienzo reeducativo es el de L. Solivetri (1985), en este artículo se apunta que el retribucionismo es puramente el pago de un daño que se ha causado a la soctedad sin que haya mayores consideraciones morales o clínicas sobre los motivos que llevaron al delincuente al delito. Se parte de que el comportamiento de la persona no se adapta al prescriro por la ley y por ello se la sanciona. No se desmerece el "ser" del delincuente, sólo su comportamiento. Pero, la reeducación "inferioriza" al delincuente ya que se supone que la "desviación" no es un "derecho" de las personas, sino una enfermedad.

23. "No hay que olvidar que la relación entre el profesional y el interno es desigual; por 


\section{ORGANIZACIÓN Y COMUNICACIÓN}

Tal vez la institución penitenciaria es la organización donde se aprecia con mayor claridad la máxima dé la Escuela de las Relaciones Humanas, según la cual, el elemento humano es lo más importante de la empresa. Pues, en efecto, si recurriéramos al concepto sistémico de organización, encontraríamos que, en el sistema dinámico de partes interdependientes tendentes a un fin, que es la organización, en la cárcel, el fin son las personas mismas. Ya sea la mera custodia o la resocialización, el fin último del aislamiento siempre pretende la modificación del comportamiento ulterior de los internos mediante la persuasión, esto es, una forma de comunicación que conscientemente pretende modificar las actitudes de aquellos a quienes se dirige. También respecto de la centralidad del elemento humano, las teorías interaccionistas de la organización basan sus investigaciones en el análisis de las redes de comunicación, de las normas, de los estilos de dirección y de la participación en las decisiones.

Las organizaciones entablan con sus miembros relaciones que se caracterizan por tener varios niveles de integración de objetivos. Existe una alta integración de objetivos cuando una organización crea las condiciones que permiten maximizar tanto objetivos personales como de la organización. Que la institución carcelaria y los internos tienen a priori objetivos distintos, lo atestigua el hecho de que el internamiento temporal en esos establecimientos raramente es voluntario, siempre reviste cierto grado de obligatoriedad.

K. Reardon (1983), resume tres modelos de interacción entre la organización y sus miembros. El primero de esos modelos se denomina modelo de intercambio. En las organizaciones que funcionan de acuerdo con ese modelo la integración de objetivos es mínima; el interno abandona sus normas personales en favor de las normas de la organización durante el período de internamiento a cambio de pagar una pena. El tipo de relación que predomina en esos ambientes es de tolerancia mútua, que consiste en una persuasión unidireccional generadora de aquiescencia. La seguridad está valorada por encima de la creatividad, y la autonomía del sujeto queda sumergida en el predominio del contexto institucional. Pero si las normas personales son importantes para el individuo, el hecho de tener que renunciar a ellas durante cierto tiempo puede generar una profunda aversión al establecimiento ${ }^{24}$.

ejemplo, en cualquier conversación tienes que autoprotegerte porque no tienes control de la información que sueltas" (IN8).

24. Algunos elementos de este modelo en la prisión se verbalizan así: «Al que tiene sus puntos de vista sobre el sistema de fases lo apartan y no le corresponde ni lo más mínimo" (IN4). "No nos dejan ser nosotros mismos, no podemos tener nuestras ideas, la opinión de uno no vale para nada" (IN9). "Nos sentimos muy utilizados y tienes que hacer teatro y fingir» (IN10). 
El segundo modelo es el de socialización. Las organizaciones que siguen este modelo operan a partir de la premisa de que la gente puede ser persuadida de que valore las actividades que ayudan a la organización a lograr sus objetivos. Se espera que los miembros abandonen o revisen las normas personales incompatibles con las normas de la organización. Las formas de persuasión características de este modelo son la aquiescencia y la acomodación. Lo mismo que en el caso del modelo de intercambio, la persuasión es unidireccional. La organización es el persuasor y el aislado el persuadido. Pero eso no significa que la aquiescencia o la acomodación del miembro no carezcan del poder de persuadir a sus superiores de que merece ser promovido en atención a su interés por la organización. La conformidad con las normas de la organización o la emulación de los superiores puede conducir a un proceso de socialización vertical (superior-subordinados) y horizontal (par-par). Aunque la mayoría de los individuos no sacrifica por entero sus normas al bien de la organización, la existencia de gratificaciones promueve un tipo de persuasión de los internos que consiste en vender la idea de que la organización está primero y las consideraciones personales después 25 .

El tercer modelo va más allá de la perspectiva unidireccional de la persuasión de los dos modelos anteriores para dar a los miembros cierta participación en la configuración de las normas y objetivos de la organización. Este es el modelo de acomodación. Una organización que adopta este modelo funciona como sigue: se toman en cuenta las necesidades y motivaciones del individuo, y la organización está estructurada y funciona de modo tal que la prosecución de los objetivos de la organización será intrínsecamente gratificante y proveerá la consecución simultánea de los objetivos del individuo. Este modelo alienta un mayor grado de autonomía del individuo que los demás, con lo cual genera un clima conducente a la cooperación y al compromiso. Como los miembros están involucrados en la solución de los problemas, en el planteamiento de objetivos y en la toma de decisiones de la organización, se estimula abiertamente la revisión de las normas recíprocas (persuasión por compromiso) y la generación de nuevas normas mutuamente satisfactorias (colaboración).

Probablemente, estos modelos no se dan en puridad en la práctica, operan como tipos ideales, y se asiste a la conjunción de elementos de unos y otros. El tercer modelo equivale a lo que J. Avelló (1986), llamaría una comunicación no alienada, es decir, una comunicación con «significación» y «sentido». La significación es el acuerdo que produce el consenso sin eliminar la diferencia en torno

25. Aunque más adelante se discutirá este modelo con mayor extensión, los siguientes discursos lo ilustran en el ámbito penitenciario: "Procuro que a través del diálogo, internos y funcionarios participen en las propuestas de la dirección» (AR1). "Lo más importante es el diálogo y la persuasión" (AR7). "A según qué internos se les intenta captar para aparentar que la cosa funciona muy bien" (IN3). 
a unos fines, que dan cuenta del sentido de la comunicación. A una organización de ese tipo aspirarían por defecto - según se desprende de sus planteamientos críticos, entre los que se puede advertir cierta línea de acuerdo- las reflexiones de M. Weber (1984) sobre la burocracia, de K. Marx (1970) sobre una organización y administración democrática (del Estado), así como las lúcidas críticas de la Escuela de Frankfurt sobre la idcología tecnocrática de la razón instrumental.

En la organización estudiada no se produce una comunicación entre todos sus miembros que articule significación y sentido. El acuerdo sobre las normas no existe, es impuesto para conseguir unos fines que sólo tienen sentido para ciertos miembros de la organización. Al disociarse cn las interacciones comunicativas significación y sentido, la finalidad de la comunicación es sólo "participar" alienadamente en una dirección que carece de sentido para los sujetos que la padecen. J. Avelló (1986) a ese tipo de comunicación la llama "ceremonia ensimismada" porque produce un proceso entrópico de identificación mediante el cual los participantes se funden en un sólo sentimiento, en una sola emoción, "ensimismamiento" en tanto que están enajenados de la significación y la diferencia. Esos procesos son característicos de la comunión mística, o sacramental, en la que los actores, al no poder diferenciarse por negarse una comunicación con sentido, pierden su identidad. Pero también los encontramos en ciertas formas organizativas de la cárcel, aunque no de un modo ureligioson ni bajo formas carismáticas de ejercicio del poder; se produce especialmente en lo que se ha descrito como modelo organizativo de intercambio.

Sobre estos tres modelos se puede afirmar que, en rigor, las interacciones comunicativas que se producen en la organización carcelaria son alienadas y que, por tanto, tampoco funcionan según el modelo de acomodación descrito.

Hasta que en 1979 la LOGP no establece el tratamiento como un instrumento facilitador de las metas resocializadoras, la institución penitenciaria sólo disponía del castigo físico en un sentido amplio (masificación, malas condiciones higiénicas y alimentarias, violencia física, etc.), para influir en el comportamiento de los internos. Obviamente, ese tipo de perstrasión intimidatoria, que operaba en un contexto de jerarquía autoritaria, ofrecía muy pocos estímulos y producia escasos efectos sobre las normas personales de los individuos.

El programa de fases experimentado en la prisión de Jóvenes de Barcelona modificará en Catalunya aquellos fundamentos teóricos de la intervención penitenciaria. A partir de 1988, momento en el que el programa de fases se reconvierte en el "Programa de Classificació en els Centres Penitenciaris", la base teórica de la intervención ya no se sustentará en el espacio de actuación jurídico-penal, sino en una disciplina con escasa incidencia hasta entonces en el ámbito de prisiones: la psicología. La argumentación que proponen sus auttores es sencilia: si se trata de modificar y establecer comportamientos, el sis- 
tema jurídico-penal ofrece el marco y las condiciones de actuación, pero no los procedimientos (F. Elejabarrieta, S. Perera y A. Ruiz, 1991). El sistema de fases desarrolla unos programas de actuación especificos encarninados a la modificación de conductas que serán puestos en marcha principalmente por los Equipos de Tratamiento ${ }^{26}$.

Idealmente, el objetivo de los Equipos de Tratamiento es lo que P. Berger y Th. Luckmann (1984) entienden por "conversión", es decir, una transformación total de la realidad subjetiva mediante la cual el individuo se desafilia del mundo que "habitaba" anteriormente rompiendo con el pasado y socializándose de nuevo (resocialización). Esto requiere que el individuo sea segregado de entre los "habitantes" de otros mundos, especialmente de los que cohabitaban con él en el mundo que dejó tras de sí. Para esta operación resulta oportuna la segregación física, cosa que efectivamente, la cárcel garantiza.

La conversión implica un cambio de identidad de los individuos, que se traduce en una modificación de su comportamiento. Los psicólogos sociales explican que esos cambios se producen por procesos de influencia social, que dan lugar a la obediencia y a la conformidad. La conformidad ha podido ser definida como un cambio en el comportamiento o las opiniones de una persona, que resulta de una presión real o imaginaria proveniente de una persona o grupo de personas ${ }^{27}$ (G. Paicheler y S. Moscovici, 1985). Pero aa la gente no le gusta que se intente influenciarla; cuando sospecha que la fuente tiene intenciones de persuadirla, se resiste a lo que percibe como un atentado a su libertad de opinión" (G. de Montmollin, 1985: 127). El autor recoge en ese trabajo diversas experiencias, según las cuales, es más eficaz un intento de persuasión que parta de una fuente creíble, que emita un mensaje cuyas características de forma y contenido sean capaces de que el receptor les preste su atención. Aunque todo ello depende del estado de ánimo del receptor, esos requisitos no garantizan la aceptación masiva del mensaje, como le critica $S$. Moscovici (1985) y tendremos ocasión de comprobar.

La credibilidad de los mensajes del Equipo de Tratamiento sería más elevada cuanto más alta fuera la percepción de competencia profesional que de ellos tuvieran los internos. La percepción de la competencia profesional es

26. Su cxposición detallada sc encuentra en el libro Programes de rehabilitació a les presons, editado por la Dirccció General de Serveis Penitenciaris i de Rebabilitació, del Departament de Justícia de la Generalitat de Catalunya, Barcelona, 1990.

27. Para J. M. Levine y M. A. Pavelchak (1985) existe obediencia cuando un individuo modifica su comportamienro a fin de someterse a las órdenes direcras de una auroridad legítima. La semejaniza cnttc la obediencia y la conformidad reside en que ambas constituyen formas de influencia social. Sin embargo difieren en cierto número de dimensiones: la diferencia de status entre la fuente de influencia y su blanco, el deseo de la fucnce de ejercer influencia y do vigilar la sumisión del blanco, y el grado de semejanza entre el comportamiento de la fuente y el del blanco. 
baja: «En líneas generales la profesionalidad percibida de los componentes del equipo técnico es baja, como se demuestra en las respuestas al cuestionario; un $62,6 \%$ de los internos encuestados opina que las personas del equipo técnico no son profesionalesn (F. Elejabarrieta, S. Perera y A. Ruiz, 1991: 158). Por otro lado, la influencia de los Equipos de Tratamiento también depende de la confianza que se les otorgue; los internos otorgarán su confianza así que los equipos les parezcan objetivos, desinteresados y sin intención de manipular o engañar. También aquí se ha comprobado que la confianza es escasa, por ejemplo: "En la otorgación de permisos se cometen injusticias" (IN7). "Los educadores están engañando a la gente» (IN4).

Además de que este tipo de opiniones desmerece a los profe sionales como depositarios de la confianza de los internos, en la medida en que los beneficios que conlleva el sistema de fases y que se comunica a los internos, no se lleve a la práctica con rigurosidad (cambios de fase según plaza disponible, permisos por motivos ajenos a los reforzadores previstos, etc.), los internos tienen dificultades para verificar que la información contenida en el programa es completamente cierta. Otro de los elementos que interviene en la efrcacia de la persuasión es el grado de atracción que provoca la fuente. La atracción que el receptor siente por la fuente es de orden afectivo y se expresa a través de una reacción emocional. El sentido común afirma que la simpatía que se siente por una persona conduce a la aceptación del punto de vista que ésta defiende. Algunas investigaciones experimentales lo han demostrado. $\mathrm{El}$ mensaje proveniente de una fuente por la que se siente simpatía tiene un mayor impacto 28 .

Si la credibilidad del Equipo de Tratamiento es baja, la confianza que le otorgan los internos es escasa, y la forma y contenido de los mensajes por medio de las actividades poco seductora ${ }^{29}$; si únicamente son capaces de ejercer una atracción por simpatía, ¿cómo y hasta qué punto el Equipo de Tratamiento obtiene obediencia o conformidad de los internos?

No es ningún descubrimiento afirmar que las relaciones de poder entre la dirección y los internos son asimétricas; sin embargo, también lo eran antes; entonces, ¿qué ha cambiado? El cambio principal ha consistido en añadir nuevas formas de interacción entre la organización y sus miembros, posibi-

28. "El educador, al ir de paisano, sc muestra más abierto, intenta constantemente ganatse la confianza de los internos porque eso forma partc de su (rabajo. Para tener éxito en su tarea necesitan mostrarse simpáticos, si no, la gente no se apunra a su actividadn (IN8).

29: "El tratamiento significa que si te portas bien te damos un caramelo y si no, un palo. Portarse bien quiere decir tener las pautas de comportamiento que ellos consideran normales, pero las pautas de conducta que eransiniten aquí no sirven para nada" (IN8). "Si evolucionaras como ellos quieren te converrirías en un vegetal; es absurdo que cuando piensas y actúas como ellos quieren ya estás preparado para vivir en sociedads (IN 10). 
litadoras de una mayor integración de objetivos personales y de la organización. El punto de partida que presentan los internos es de una amplia aversión a las propuestas reeducadoras del Equipo de Tratamiento. Su percepcion de la cárcel es la de una organización que les impone un cambio de comportamiento sin ofrecer nada a cambio ${ }^{30}$. No obstante, este tipo de percepción de su estancia en la institución, aun siendo generadora de una profunda aversión, no se traduce en acciones de defensa colectiva de la identidad grupal: "las fases a nadie le gustan, pero nadie se queja” (IN8). Precisamente el elemento de interacción que se ha añadido, el sistema de fases, propicia un posicionamiento distinto para cada grupo de presos según la relación que establecen con la organización. El Equipo de Tratamiento ha de conseguir al máximo sus objetivos institucionales a cambio de los servicios que presta; mientras que los internos procuran obtener el máximo de servicios a cambio de la mínima modificación en sus normas de comportamiento. Se trata de una forma de interacción comunicativa que opera como instrumento de manipulación para lograr la cooperación de los internos. J. M. Levine y M. A. Pavelchak (1985) explican que una poderosa razón para conformarse (cambio de comportamiento o de opiniones) es el deseo de evitar los castigos y/o el deseo de adquirir recompensas. El objetivo manifiesto de la institución es cumplir el mandato legal resocializador, aunque el objecivo latente es el mantenimiento del orden interior. En ambos casos, la estrategia de la organización a corto plazo consiste en modificar las pautas de comportamiento de los internos forzando una adaptación mediante una combinación de castigo y persuasión. En ese proceso se acaba produciendo una selección entre los internos, a través de la cual los más proclives a exhibir un cambio de actitud son recompensados 31 .

La conformidad aparece como una forma de negociación entre el interno y la institución a propósito sobre la manera de definir la realidad, pero frente a la distribución asimétrica del poder, y de la definición sobre la necesidad y condiciones de la reeducación, los internos se defienden con la desidia frente a las actividades propuestas que no responden a sus intereses; o bien, manteniendo sus hábitos de conducta de forma clandestina. Esa resistencia a la influencia es lo que H. C. Kelman (1961) llamó "conformidad simulada", que consiste en aceptar de forma pública un comportamiento o un sistema de va-

30. "El educador, el criminólogo, el psicólogo no rienen derecho a hacer cambiar a la gente" (IN6). "Los internos son muy recelosos de su identidad y la quieren mantener por encima de rodo. La colaboración con la insrirución está mal vista, y ello hace que desconfíen de todo lo que viene de la institucionn (AT1).

31. «Intentas seguir las normas sin creérrelas esperando obtener alguna ventaja que siempre te prometen" (IN3), "Aquí lo único que se quiere es la libertad, y si por la libertad hay que engañar al equipo de tratamiento, se le engañan (ING). 
lores sin adherirse a ellos de forma privada (conversión o internalización) ${ }^{32}$. En apariencia, los individuos se someten a fin de evitar ciertos perjuicios: partes, regresión de fase, negación de permisos. Pero conservan sus creencias y están dispuestos a cambiar su comportamiento desde el momento en que las circunstancias ya no se lo impongan ${ }^{33}$.

La institución carcelaria emplea crecientemente un conjunto de recursos comunicativos, que si bien posibilitan un alto grado de consecución de obje. tivos organizativos, como la reducción del conflicto interior, y en menor medida personales, generan un tipo de interacción en la cual la cooperación consiste en distribuir selectivamente una serie de recompensas que, al tiempo que: rompen las identidades grupales, instauran nuevas formas disciplinares (complicidad pública con el poder para evitar la marginación individual), cuyos mecanismos internos obedecen a procesos sociales, con los que guardan ciertas homologías. En la prisión, esos mecanismos ordenan una jerarquía de respuestas al poder por parte de los internos, que combina vigilancia, beneficios y sumisión ${ }^{34}$. La conformidad simulada es el resultado de aplicar el sistema de fases como forma de gestión que, lejos de servir a las metas resocializadoras, conileva altos costes personales e inaugura nuevas formas de castigo ${ }^{35}$. Además de ello, para que las estrategias de conformidad simulada se puedan lievar a término, es menester ciertas habilidades que se relacionan con el capital cultural de los individuos ${ }^{36}$. Para colaborar con la institución no es suficiente es. tar dispuesto a una comunicación alienada, sino disponer también de un conjunto de destrezas. Entre ellas, el lenguaje, que opera a partir de códigos

32. "Los internos encienden las fases como una forma de promocionar a base de simulación. Así que la fase es más alta, la simulación es mayor, y a la inversa. Amenos punición más simulacion" (AT1), "A los internos les pedimos y enseñamos a facilitar la crearividad simula" doras (AT6).

33. "Los internos no ven el objetivo ni la necesidad de tratarse, piensan que ya están bien socializados" (AT1). "El interno no participa para tratarse, sino porque obtiene ganancias secundarias" (AR2). "Cuando la presión desaparece, fácilmente pucdes volver a caern (IN8).

34. "A más fase hay más control por parte del equipo. En el módulo III y IV la gente está muy pillada; su rebeldia la van aparcando y engañan al equipo para poder conscguir un permiso... Aqui te lo has de currar mucho, y cuanto más participas y más trabajas, más cosas te dan a cambion (IN6). "En el IV se siente mucho más miedo y se está más obsesionado por los permisos que en orros módulos. Eso es un chantaje a la conciencian (IN8).

35. "Aquí no te tratan como un delincuente sino como un ser diferente" (IN8) "Los profesionales son profesionales del castigo psicológico" (IN6). "El verdugo de la Edad Media se ha convertido en un funcionario titulado" (IN3). "Ahora lo que más se practica es el maltrato psicologico, no está penado y no deja huellas visibles" (AR5).

36. "Los del I y II, tienen dificultades para engañar al siscema" (IN3). "Los que esrán en el IV se enrollan mejor con los educadores porque tienen facilidad de palabra, hay que ganarse la confianza. Fs un sistema competitivo como en la escuela, y por eso llegan al IV los que mejor compitenn (IN8). 
lingüísticos, actúa como factor constitutivo y discriminante de los grupos sociales (B. Bernsteinn, 1988).

\section{A MODO DE CONCLUSIONN}

En las páginas precedentes se ha pretendido traer a colación los principales resultados de una investigación sobre la prisión. Tal vez la conclusión más interesante sea que, lejos de cualquier eficacia resocializadora, la moderna clasificación y el sistema de fases aplicado por la Generalitat de Catalunya ${ }^{37}$, son generadores de nuevas formas disciplinares y de producción del orden en el interior de la cárcel.

La dimensión clave sobre la que opera la Administración Penitenciaria es el espacio. Su descentralización conlleva la fragmentación de los internos en distintas categorías que, en forma de estratos abiertos, permiten una movilidad social ascendente y descendente. La ideología meritocrática, asociada a los premios y castigos, que define la institución, desarticula las identidades colectivas al tiempo que desactiva los potenciales de conflicto.

La fragmentación del espacio y la división de los internos se conjuga con un ordenamiento de condiciones de vida en la prisión. De ese modo, segmentando el espacio y ubicando en él a distintas «subclases» de presos, tienden a diluirse las relaciones horizontales por medio de una nueva codificación espacial. La multiplicación de espacios y de grupos de individuos, además de dificultar la mera coincidencia, está asociada a la posibilidad de intercambiar beneficios penitenciarios por autorrepresión. Las distintas combinaciones de beneficios y sumisión se traducen en una «deshomogeneización de condiciones de vida» debido a la fragmentación social en la cárcel.

El acceso a las ventajas penitenciarias se basa en el grado de participación y compromiso con los objetivos de la dirección del establecimiento. La variable fundamental que dinamiza el sistema y justifica la estancia en una u otra fase son las actividades que propone el Equipo de Tratamiento. Las actividades se postulan como reeducadoras para que la pena pueda definirse como una ayuda secularizada; así, las nuevas autoridades disciplinares, investidas de un poder pedagógico y legitimadas por un «saber comunicativo», son los evaluadores de la participación de los internos en la consecución de los fines de la dirección.

37. Recuérdese que el día 28 de diciembre de 1983 se publica en el BOE y en el DOGC el Real Decreto de traspaso de servicios del Estado a la Generalitat de Catalunya sobre Administración Penitenciaria. Ese traspaso era producto del desarrollo del Estatuto de Autonomía de 1979 (Art. 11.1), en el que se establece que corresponde a la Generalitat la ejecución de la legislación del Estado en materia penitenciaria. 
La operacionalización del uso del espacio y del tiempo genera un nuevo tipo de relaciones disciplinares que modifica la expresión del conflicto y la construcción del orden. La "acción colectiva", que respondía a unas condiciones de homogeneidad de cláse y de clasificación, es sustituida por una "dinámica privada" como medio para mejorar las condiciones de existencia; así, la solidaridad horizontal se trastoca en una lealtad vertical que, como escribía al principio, hace cómplice al individuo de su propia represión.

No obstante, la eficacia de la clasificación y de los programas de rehabilitación en la producción del orden social en la cárcel, no parece que sean efectivos para los declarados fines de reinserción. Los internos aprenden a simular una conformidad con los objetivos de la dirección, tanto para evitar ciertos perjuicios como a fin de obtener ciertas ventajas; pero conservan sus creencias y están dispuestos a cambiar su comportamiento desde el momento en que las circunstancias ya no se lo exijan. La conformidad simulada es la principal consecuencia de la gestión de la cárcel. Si el objetivo de la institución es el mantenimiento del orden a cambio de beneficios penitenciarios, el objetivo se cumple; pero si la ejecución de la pena debe orientarse hacia la reinserción social, como señala la Constitución, los datos empíricos no permiten corroborar ese propósito.

\section{BIBLIOGRAFIA CITADA}

AA.VV, (1982), Estudios penales: libro homenaje al Prof. J. Antón Oneca, Salamanca, Ediciones de la Universidad de Salamanca.

AA.VV. (1985), Lecciones de Derecho Penitenciario. Madrid, I.C.E, Universidad de Alcalá de Henares.

Adelantado Gimeno, J. (1992), Orden cultural y dominación. La cárcel en las relaciones disciplinarias, Tesis doctoral microfilmada, Departamento de Sociología, Universidad Autónoma de Barcelona.

Alarcón Bravo, J. (1989), «El tratamiento penitenciario en el primer decenio de la LOGP». Madrid, Revista de Estudios Penitenciarios. Extra n ${ }^{\circ} 1$, pp. 11-23.

Aniyar de Castro, L. (1985), «L'educazione come forma del controllo socialen, Bolonia, Dei delitti e delle pene. Anno III, $\mathrm{n}^{\circ}$ 1, gennaio-apprile, pp. 131-148.

Avello Florez, J. (1986), «La ceremonia ensimismada: un ensayo sobre alienación y pacto en la comunicación", Madrid, R.E.I.S., no 33, pp. 83-119.

Baratta, A. (1986), Criminología critica y critica del derecho penal, Madrid. Siglo XXI. Edición original en italiano, 1982

Baratta, A. (1988), «Anormalidad y marginación. El lugar del educador penitenciario en la sociedad", Barcelona, Papers d'Estudis $i$ Formació, no 4, pp.. 23-28, Generalitat de Catalunya, Departament de Justícia. 
Bergalli, R. (1976), ¿Readaptación social por medio de la ejecución penal? Madrid, Publicaciones del Instituto de Criminología.

Berget, P. y Luckmann, Th. (1984), La construcción soctal de la realidad, Buenos Ajres, Amorrorru, Primera edición, en inglés 1966.

Bernstein, B. (1988), Clases, códigos y control. Hacia una teoria de las transmisiones educativas: II, Madrid, Akal, primera edición, en inglés 1975.

Cohen, S. (1988), Visiones de control social. Delitos, castigos y clasificaciones, Barcelona, (PPU) Promociones y Publicaciones Universitarias, edición original en inglés 1985.

Cohen, S. and Scull, A. (Eds.) (1985), Social Control and the State, Oxford, Basil Blackwell.

Elejabarrieta, F., Perera, S. y Ruiz, A. (1991), La representación del sistema de clasificación interior en los centros penitenciarios de Cataluña, Barcelona, Centre d'Estudis Jurídics i Formació Especialitzada, Departamen de Justícia, Generalitat de Catalunya.

Fortuna, F. Saverio (Ed.) (1985), Operatori penitenziari e legge di riforma. I protagonisti dellideologia penitenziaria, Milano, Franco Angeli.

Foucault, M. (1988), Vigilar y castigar. Nacimiento de la prisión, Madrid, Sigto XXI, edición original en francés 1975.

García Garcia, J. (1985), "Las técnicas de modificación de conducta: su aplicación penireciaria", Madrid, Cuadernos de Politica Criminal, n² 26, pp. 349-369.

García García, J. (1987a), "Efectos del cncarcelamiento: Investigación e intervención (Programa para mejorar el clima social en una de las fases del C. P. "Ocaña II")", Madrid, Revista de Estudios Penitenciarios, n² 237 , pp. 43-55.

García García, ]. (1987b), "La prisión como organización y medio total de vida", Madrid, Revista de Estudios Penitenciarios, n 238 , pp. 33-45.

García-Pablos de Molina, A. (1984), Estudios penales, Barcelona, Bosch.

Garrido Genovés, V. (1986), "El tratamiento penitenciario, en la encrucijada", Madrid, Revista de Estudios Penitenciarios, no 236, pp. 21-31.

Garrido Genovés, V. (1987), "El tratamiento penitenciatio, en la encrucijada (II)", Madrid, Revista de Estudios Penitenciarios, $n^{\circ} 237$, pp. $119-123$.

Garrido Guzmán, I. (1989), "Los permisos penitenciarios", Madrid, Revista de Estudios Penitenciarios, extra n० 1 , pp. 89-102.

Generalitat de Catalunya (1989), Centre Penitenciari "Quatre Camins", Departament de Justícia.

Generalitat de Catalunya (1990a), Programes de rehabilitació a les presons. Departament de Justicia, Direcció General de Serveis Penitenciaris i de rehabilitació.

Generalitat de Catalunya (1990b), Programa de classificació interior C. P. "Quatre Camins", Sots-direcció de Tractament, Departament de Justícia.

Giner, S. y Pérez Yruela, M. (1979), La sociedad corporativa, Madrid, Centro de Investigaciones Sociológicas.

Habermas, J. (1981), La reconstrucción del materialismo histórico, Madrid, Tautus, edición original en alemán 1976.

Habermas, J. (1987a), Teoria de la acción comunicativa, I. Racionalidad de la acción y racionalización social, Madrid, Taurus, cdición original en alemán 1981. 
Habermas, J. (1987b), Teoria de la acción comunicativa, II. Crítica de la razón funcionalista, Madrid, Taurus, edición original en alemán 1981.

Kelman, H. C. (1961), "Processes of opinion change”, Illinois, Public Opinion Quarterly, $\mathrm{n}^{\circ} 25$, pp. $57-58$.

Lea, J. (1979), "Disciplina e sviluppo capitalista", Bolonia, La questione criminale, anno $\mathrm{V}$, maggio-agosto, pp. 217-235.

Lerena Aleson, C. (1986), Escuela, ideologia y clases sociales en España, Barcelona, Ariel, primera edición en 1976.

Levine, J.M. y Pavelchak, M.A. (1985), "Conformidad y obediencia", en Moscovici, S. Psicologia social, I. Influencia y cambio de actitudes. Individuos y grupos, BatceIona, Paidós, pp. $41-70$.

Lowman, J., Menzies, R.J. and Palys, T.S. (Eds.) (1987), Transcarceration: Essays in the Sociology of Social Control, Aldershot, Gower.

Mapelli Caffarena, B. (1983), Principios fundamentales del sistema penitenciario español, Barcelona, Bosch.

Mapelli Caffarena B. (1985), "Sistema progresivo y tratamiento" en AA.VV. (1985), Lecciones de Derecho Penitenciario, pp. 139-171.

Mapelit Caffarena, B. (1986a), "Criminología crítica y ejecución penal" Barcelona, Poder y Control, no 0, pp. 175-188.

Mapelli Caffarena, B. (1986b), "I.a clasificación de los internos", Madrid, Revista de Estudios Penitenciarios, $\mathrm{n}^{\circ}$ 236, pp. 99-125.

Martorell Fabregat, M. (1989), El procés d'incorporaciós social en una mostra qualitativa d'ex- reclusos: la incidencia de la presó en els setus usuaris, Barcelona, Generalitat de Catalunya, Departament de Justícia, Centre d'Estudis i Formació.

Marx, K. (1970), Contribución a la critica de la filosofia del derecho de Hegel, Barcelona, Martínez-Roca.

Melossi, D. (1980), "Las estrategias de control social en el capicalismo", Papers, $n^{\circ} 13$. pp, 165-196. Este artículo es la versión castellana de "Oltre il Panopticon. Per uno studio delle strategie di controllo sociale nel capitalismo del ventesimo secolo", Bolonia, La questione criminale VI/2-3, maggio-dicembre 1980, pp 277-361.

Melossi, D. (1990), "Social Control and Punishment Beyond the "Panopticon": Imprisonnment as Symbolic Action in Mass Democracies." Madrid, Ponencia presentada al XIIo Congreso Mundial de Sociología, 32 págs.

Monymollin, G. (1985), "El cambio de actitud", en Moscovici, S. Psicologia social, I. Influencia y cambio de actitudes. Individuos y grupos, pp 117-173.

Moscovoci, S. (Ed.) (1985), Psicologia social, I. Influencia y cambio de actitudes. Individuos y grupos. Barcelona, Paidós, edición otiginal en francés 1984.

Múñoz Conde, F. (1982), «La resocialización del delincuente. Análisis y crítica de un mitom en AA.VV (1982), Estudios Penales. Libro homenaje al Prof. J. Antón Oneca, pp. 388-399.

Múñoz Conde, F. (1985), Derecho penal y control social Jerez, Fundación Universitaria de Jercz.

Paicheler, G. y Moscovici, S. (1985), "Conformidad simulada y conversión" en Moscovici, S. Psicologia social, I. Influencia y cambio de actitudes. Individuos y grupos, pp. 175-208. 
Pasukanis, Evgeny B. (1970), La théorie générale du droit et le marxisme, Paris, EDI. Reardon, Katheleen K. (1983), La persuasión en la comunicación, Barcelona, Paidós, edición original en inglés 198 I.

Redondo Illesca, S. (1990a), «Elementos clave para una psicología penirenciaria aplicada», Valencia, Ponencia presentada al II Congreso del Colegio Oficial de Psicólogos, pp. 73-77.

Redondo, S., Garrido, V. y Pérez, E. (1988), «Entorno penitenciarto y competencia psicosocial: un modelo integrado de reinserción social", Barcelona, Papers d'Estudis i Formació, $n^{\circ}$ 4, pp. 9-21, Generalitar de Catalunya, Departament de Justícia.

Redondo S., Roca, M. y Pérez, E. (1991), «Análisis de conducta aplicado en una prisionn: El sistema de fases progresivas", Madrid, Rev. Papeles del Psicólogo, época II, $n^{\circ} 48$, pp. 58-63.

Redondo, S., Roca, M., Pérez, E., Sánchez, A. y Deumal, E. (1990), "Diseño ambiental de una prisión de jóvenes. Cínco años de evaluación’, Valencia, Rev. Delincuencia, vol. II, $\mathrm{n}^{\circ} 3$, pp. 321-357.

Redondo, S., Roca, M. y Portero, P. (1986), «Aproximación conductual en un centro penirenciario de jóvenes: un sistema de fases progresivas", Madrid, Revista de Estudios Penitenciarios, $\mathrm{n}^{\circ} 236$, pp. 127-140.

Sancha Mata, V (1987), "Clima social: sus dimensiones en prisión", Madrid, Revista de Estudios Penitenciarios, $\mathrm{n}^{\circ}$ 237, pp 99-1 18.

Scull, A. (1984), Decarceration. Community Treatment and the Deviant. Cambridge, Polity Press. Esra edición incluye: "Decarceration reconsidered" aparecida postetiormente en J. Lowman, R.J. Menzies y T.S. Palys (1987), Trans-carceration: Essays in the Sociology of Social Control, pp. 316-337.

Soliveti, L. (1985), "Società e risocializzazione: il ruolo degli esperti nelle attività di trattamento rieducativon en Fortuna, F.S. (1985), Operatori penisenziari e legge di riforma, pp. 225-265.

Stame, F. (1979, "Teoria dello Stato e controllo sociale», Bolonia, La questione criminale, Anno $\mathrm{V}$, maggio-agosto, pp 185-215.

Weber, M. (1984), Economia y sociedad. Esbozo de sociologia comprensiva, México, FCE, edición original en alemán 1922. 